Check for updates

Cite this: RSC Adv., 2018, 8, 2667

Received 7th December 2017

Accepted 2nd January 2018

DOI: $10.1039 / c 7 r a 13115 a$

rsc.li/rsc-advances

\section{Theoretical and experimental studies of the influence of gold ions and DMH on cyanide-free gold electrodeposition}

\author{
Xuefeng Ren (D) *a and Maozhong An*b
}

\begin{abstract}
Quantum chemical calculations based on density functional theory (DFT) were employed to determine an appropriate gold source for gold electroplating and to ascertain the stable structures of gold-complexes in cyanide-free electrolyte. Based on the charge distribution of 5,5-dimethylhydantoin (DMH) and the bonding energy of gold complexes, $\mathrm{Au}^{3+}$ is the appropriate gold source for $\mathrm{DMH}$-based gold electroplating electrolyte to get greater cathodic polarization and $\left[\mathrm{Au}(\mathrm{DMH})_{4}\right]^{-}$with $2 \mathrm{~N}(4)-\mathrm{Au}$ coordination structure is the most stable form of gold ion in the electrolyte. The influence of DMH, used as the complexing agent, on electrochemical behaviors was investigated using cathodic polarization, cyclic voltammetry, and chronoamperometry measurements. With DMH as the complexing agent, the cathodic polarization of gold electrodeposition was significantly enhanced. DMH concentration was determined as $0.30 \mathrm{~mol} \mathrm{~L}^{-1}$ based on the investigation of the influence of the DMH concentration on cathodic polarization and gold electrodeposit micromorphology. The kinetic features based on cyclic voltammogram measurements revealed that the electrodeposition was an irreversible process under diffusion control with $0.30 \mathrm{~mol} \mathrm{~L}^{-1} \mathrm{DMH}$ as the complexing agent. The ion and electron transfers were obviously inhibited by $\mathrm{DMH}$. The gold electrodeposition process displayed progressive nucleation according to the Scharifker and Hills nucleation model with various applied potentials. The growth rate of the crystal nucleus was reduced by $\mathrm{DMH}$ and promoted by a negative shift of $E_{\mathrm{ap}}$.
\end{abstract}

\section{Introduction}

Gold deposits are widely used for decorative and functional applications owing to their beautiful appearance and superior

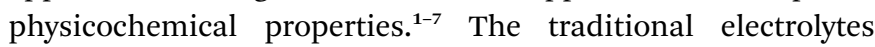
employed for gold plating contain the cyanide-based complex $\left[\mathrm{Au}(\mathrm{CN})_{2}\right]^{-}$(ref. 8 and 9) as the source of gold, which releases free cyanide ions during the plating process. Cyanide is an extremely toxic chemical, yielding high risks to human health and the environment. ${ }^{10}$ Moreover, cyanide electrolytes have poor compatibility with the positive photoresists used in the microelectronic industries when the release of free cyanide occurs during the reduction of $\left[\mathrm{Au}(\mathrm{CN})_{2}\right]^{-}$, which can result in photoresist cracking. ${ }^{11,12}$ The development of cyanide-free gold electrolytes is urgently needed and alternative complexing agents for gold plating are being investigated to avoid those problems. ${ }^{13-15}$ Nowadays, the main complexing agents studied and used for cyanide-free gold plating electrolytes are sulfite and thiosulfate. ${ }^{16-18}$ Unfortunately, these cyanide-free gold

${ }^{a}$ School of Food and Environment, Dalian University of Technology, Panjin, 124221, China.E-mail: rxfhit@163.com; renxuefeng@dlut.edu.cn

${ }^{b}$ State Key Laboratory of Urban Water Resource and Environment, School of Chemistry and Chemical Engineering, Harbin Institute of Technology, Harbin, 150001, China. E-mail:mzan@hit.edu.cn plating electrolytes still suffer from problems of instability, which limits their further study and application. ${ }^{19}$

A possible alternate to cyanide is DMH, a low cost and commercially available derivative of hydantoin with good solubility and stability in aqueous solutions in a large temperature range. DMH is a promising environmental friendly complexing agent, which can coordinate with many metal ions. ${ }^{20-22}$ The DMH-based electrolyte is simple, stable, environmentally friendly, and compatible with various chemicals and substrates. One $\mathrm{Au}^{3+}$ ion and four $\mathrm{DMH}^{-}$ions can form a coordination complex $\left[\mathrm{Au}(\mathrm{DMH})_{4}\right]^{-}$in the electrolyte. ${ }^{23}$

It is important to get an insight into the bonding interaction of gold ions and $\mathrm{DMH}^{-}$ions in the electrolyte as well as study the mechanisms of action of $\mathrm{DMH}$ on the gold electroplating process. These insights will provide important guidance to perfect the DMH-based gold electroplating electrolyte. Quantum chemical calculation and molecular modeling are fast emerging areas of research for the modeling of small chemical and biological systems in order to understand and predict their behaviors at the molecular level. ${ }^{24-28}$ Quantum chemical calculations based on DFT have become an effective technique for the calculation of many natural systems in pharmacology, chemistry, and biology. ${ }^{29-32}$ The basic foundation of DFT states that the external potential is a functional of the group-state density, and the density (an observable in 3D space) is used to 
describe the complicated physics behind the interactions between electrons. ${ }^{33-36}$ DFT has made an unparalleled impact on the application of quantum mechanics to interesting and challenging problems in chemistry for the past several decades. ${ }^{37-39}$ In coordinate systems, bonding interactions between metal ions and complexing agents can be predicted and investigated by quantum chemical calculations. ${ }^{\mathbf{4 0 - 4 3}}$

In this work, the charge distributions of DMH as well as the structures of gold(I) and gold(III) complexes were studied by quantum chemical calculations to determine the appropriate gold source for the gold electroplating. The role of DMH used as the complexing agent in cyanide-free gold electroplating electrolyte was investigated by cathodic polarization, cyclic voltammetry, and chronoamperometry. The morphology of the gold electrodeposits was evaluated by scanning electron microscope (SEM).

\section{Experimental}

\subsection{Quantum chemical calculations}

To determine the appropriate gold source for the gold electroplating and predict the possible structures of the complexing structures, we coordinated $\mathrm{Au}^{+}$and $\mathrm{Au}^{3+}$ with $\mathrm{DMH}^{-}$. Quantum chemical calculations based on DFT were employed to study the charge distribution of the DMH molecule. Based on the charge distribution of the DMH molecule, the possible structures of gold(I) and gold(III) complexes were initially identified. Then the stable structures and bonding energies of gold ions and $\mathrm{DMH}$ were further studied by quantum chemical calculations.

All quantum chemical calculations were carried out using the B3LYP functional method. In the geometry optimization and single point energy calculation, the $6-311++\mathrm{G}^{* *}$ basis set was used for the $\mathrm{C}, \mathrm{N}, \mathrm{O}$, and $\mathrm{H}$ atoms of the studied systems, except $\mathrm{Au}$ ions, for which we used the LANL2DZ ECP basis set. All calculations in these systems under investigation were performed using the Gaussian 09 program package at $318 \mathrm{~K}$ with water as the solvent in the IEFPCM theoretical model. The bonding energies $E_{\text {bonding }}$ between $\mathrm{Au}^{+}$or $\mathrm{Au}^{3+}$ and $\mathrm{DMH}^{-}$were calculated using eqn (1) and (2), where $E_{\mathrm{Au}^{+}}, E_{\mathrm{Au}^{3+}}, E_{\mathrm{DMH}}, E_{\mathrm{H}_{2} \mathrm{O}}$, and $E_{\mathrm{H}_{3} \mathrm{O}^{+}}$were the energy of $\mathrm{Au}^{+}, \mathrm{Au}^{3+}, \mathrm{DMH}, \mathrm{H}_{2} \mathrm{O}$, and $\mathrm{H}_{3} \mathrm{O}^{+}$, respectively, and $E_{\text {complexes }}$ was the energy of the gold complex.

$$
\begin{aligned}
& E_{\text {bonding }}=E_{\mathrm{Au}^{+}}+2 E_{\mathrm{DMH}}+2 E_{\mathrm{H}_{2} \mathrm{O}}-E_{\text {complexes }}-2 E_{\mathrm{H}_{3} \mathrm{O}^{+}} \\
& E_{\text {bonding }}=E_{\mathrm{Au}^{3+}}+4 E_{\mathrm{DMH}}+4 E_{\mathrm{H}_{2} \mathrm{O}}-E_{\text {complexes }}-4 E_{\mathrm{H}_{3} \mathrm{O}^{+}}
\end{aligned}
$$

\subsection{Measurements}

$\mathrm{Au}^{3+}$ is coordinated by $\mathrm{DMH}^{-}$to form the structure of $\left[\mathrm{Au}(\mathrm{DMH})_{4}\right]^{-}$as the form of main salt and the concentration of $\mathrm{HAuCl}_{4}$ in the electrolyte was determined as $0.025 \mathrm{~mol} \mathrm{~L}^{-1}$, and the various studied complexing agent $\mathrm{DMH}$ concentrations were 0 , $0.10,0.20,0.30,0.45$, and $0.60 \mathrm{~mol} \mathrm{~L}^{-1}$. The conductive salt $\mathrm{K}_{2} \mathrm{CO}_{3}$ concentration was $0.36 \mathrm{~mol} \mathrm{~L}^{-1}$. Solutions used for Au deposition and electrochemical measurements throughout this work were prepared with analytical reagents from Sinopharm Chemical
Reagent Co. Ltd using deionized water. The $\mathrm{pH}$ of all these electrolytes was maintained at 10.0 by $\mathrm{KOH}$ to guarantee the stability of the gold(III) complexes and avoid a chemical replacement reaction occurring between the gold(III) complexes and the metal substrate.

All electrochemical measurements were performed in a typical three-electrode cell using an electrochemical workstation at $318 \mathrm{~K}$. Platinum foil with $1 \mathrm{~cm}^{2}$ surface area and a saturated calomel electrode (SCE) were employed as the counter electrode (CE) and the reference electrode (RE), respectively. A platinum rotating disk electrode (Pt-RDE) with a diameter of $5 \mathrm{~mm}$ (with $0.19625 \mathrm{~cm}^{2}$ surface area) was employed as the working electrode (WE) for the cathodic polarization measurements, and a glassy carbon electrode (GCE) with a diameter of $3 \mathrm{~mm}$ (with $0.07065 \mathrm{~cm}^{2}$ surface area) was used for cyclic voltammograms and chronoamperometry measurements.

Gold electrodeposits were deposited on a copper sheet coated with a nickel deposit. Gold electrodeposits were all prepared under galvanostatic conditions $\left(8 \mathrm{~mA} \mathrm{~cm}{ }^{-2}\right)$ with mild agitation at $318 \mathrm{~K}$ for $5 \mathrm{~min}$, either in the absence or presence of different $\mathrm{DMH}$ concentrations. The surface morphologies and microstructure of the gold electrodeposits were studied by field emission scanning electron microscopy (FE-SEM, Hitachi SU8000).

\section{Results and discussion}

\subsection{Quantum chemical calculations}

In the gold electrodeposition process, $\mathrm{Au}^{+}$and $\mathrm{Au}^{3+}$ are the most commonly used main salts as gold sources; the selection of the main salt for gold electrodeposition is important for the performance of the gold deposition. Quantum chemical calculations are time- and resource-saving processes for the selection of gold ions without consumption of the extremely precious gold, the same as the investigation of $\mathrm{Ag}$ and $\mathrm{Zn}-\mathrm{Ni}$ electrodeposition by theoretical and experimental studies. ${ }^{\mathbf{4 4 - 4 6}}$

In this work, the charge distributions of DMH as well as the structures of gold(I) and gold(III) complexes were studied by quantum chemical calculations to determine the appropriate

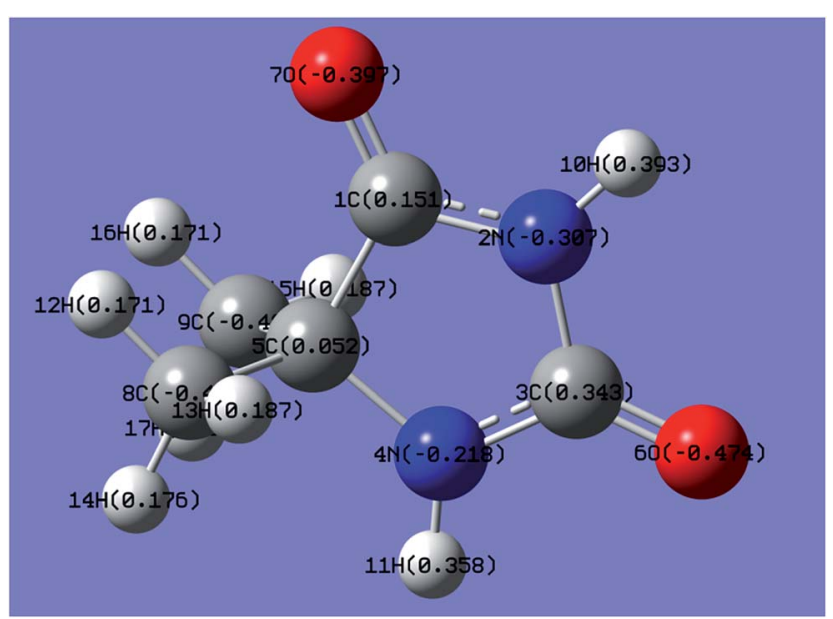

Fig. 1 Molecular structure and charge distribution of DMH with atom symbols (unit of e). 
gold source for the gold electroplating. The molecular structure and charge distribution of DMH (a heterocyclic structure organic molecule) with atom symbols is displayed in Fig. 1.
As shown in Fig. 1, $2 \mathrm{~N}(-0.307)$ and $4 \mathrm{~N}(-0.218)$ of $\mathrm{DMH}$ were the most likely atoms to form coordinate bonds with gold ions. Three gold(I) complexes and 12 gold(III) complexes were
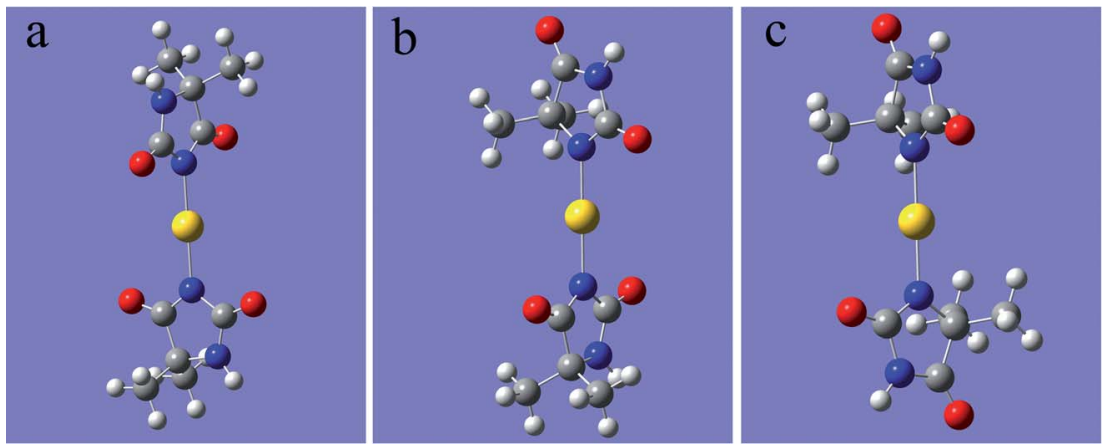

Fig. 2 Optimized structures of the gold(I) complexes with DMH (the yellow balls represent Au; the symbols of other atoms are shown in Fig. 1), (a) $2 \mathrm{~N}(2)-\mathrm{Au}$, (b) $2 \mathrm{~N}(1)-\mathrm{Au}-4 \mathrm{~N}(1),(\mathrm{c}) 4 \mathrm{~N}(2)-\mathrm{Au}$.

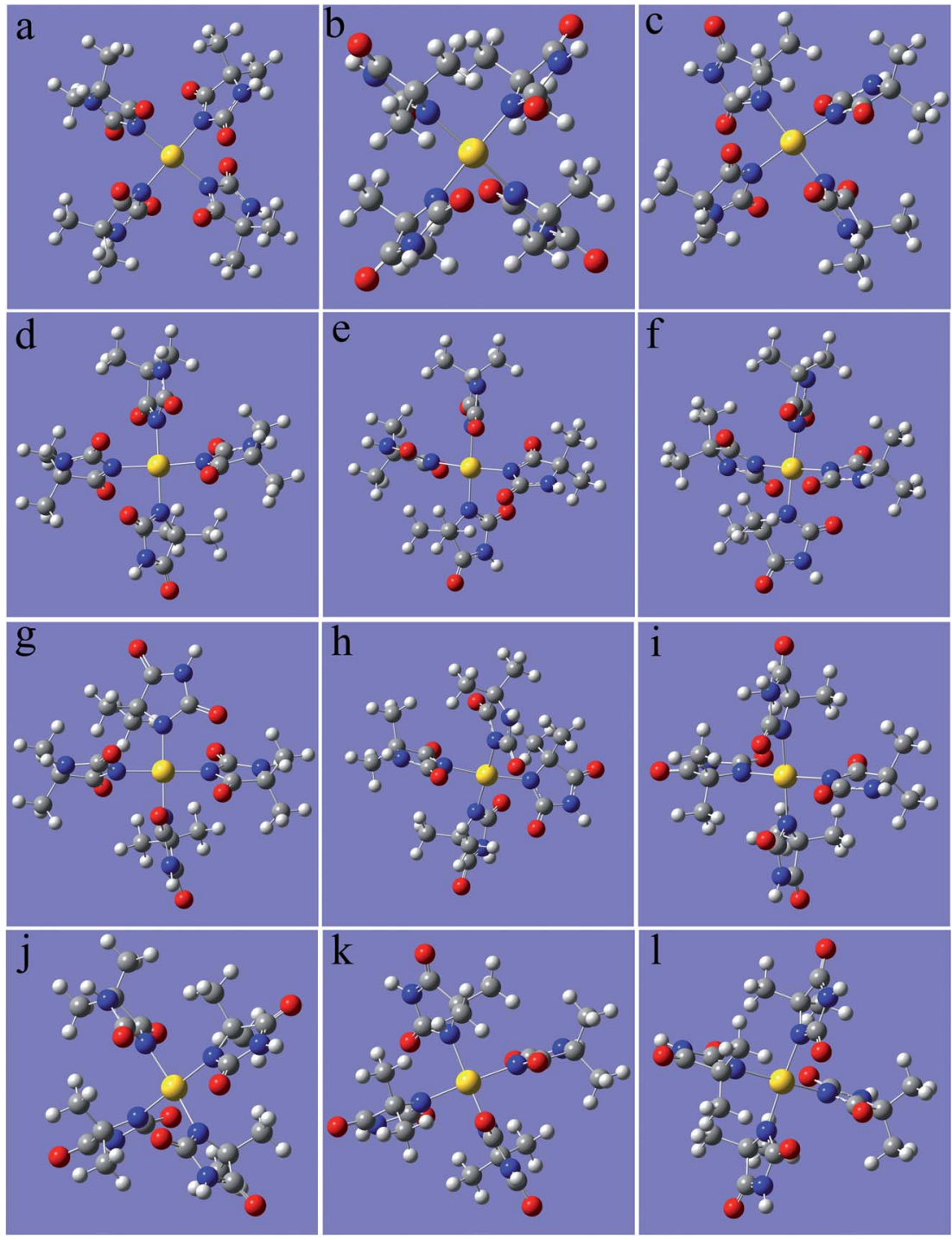

Fig. 3 Optimized structures of the gold(III) complexes with DMH (the yellow ball represents $\mathrm{Au}$, the symbols of the other atoms are shown in Fig. 1), (a) $2 N(4)-A u$, (b) $4 N(4)-A u$, (c) $2 N(3)-A u-4 N(1)$, (d) $2 N(3)-A u-4 N(1)$, (e) $2 N(3)-A u-4 N(1),(f) 2 N(3)-A u-4 N(1),(g) 2 N(2)-A u-4 N(2)$, (h) $2 N(2)-A u-4 N(2)$, (i) $2 N(1)-A u-4 N(3),(j) 2 N(1)-A u-4 N(3),(k) 2 N(1)-A u-4 N(3),(l) 2 N(1)-A u-4 N(3)$. 
possible structures of gold complexes in the electrolyte according to the charge distribution of DMH. The stability of the gold(I) and gold(III) complexes in the gold electroplating electrolyte was studied by quantum chemical calculations. The bonding energies of different complexes under study were calculated at the B3LYP/GENECP level. Fig. 2 and 3 present the optimized structures of the gold(I) and gold(III) complexes with $\mathrm{DMH}$, respectively, based on their electronic properties.

As shown in Fig. 2 and 3, these three gold(I) complexes and 12 gold(III) complexes were stable structures in the DMH-based electrolyte. The key geometric parameters and bonding energies of these studied complexes are summarized in Tables 1-3.

In conclusion from Tables 1-3, the large and similar bonding energies ( $\left.E_{\text {bonding }}\right)$ indicate that these three possible structures of gold(I) complexes and 12 possible structures of gold(III) complexes were all stable structures in the gold electroplating electrolyte. With total bonding energy of $-71.92 \mathrm{~kJ} \mathrm{~mol}^{-1}, 4 \mathrm{~N}(2)-\mathrm{Au}$ of $\left[\mathrm{Au}(\mathrm{DMH})_{2}\right]^{-}$is the most stable structure of the gold(I) complexes in the DMH-based gold electroplating electrolyte. In contrast, the structure $2 \mathrm{~N}(4)-\mathrm{Au}$ with bonding energy of $-1100.95 \mathrm{~kJ} \mathrm{~mol}^{-1}$ was the most possible and stable structure of gold(III) complexes in the DMHbased gold electroplating electrolyte. The higher bonding energy of gold(III) complexes than that of gold(I) complexes

Table 1 Energetic data calculated with B3LYP for $\mathrm{Au}^{3+}, \mathrm{Au}^{+}, \mathrm{DMH}$, $\mathrm{H}_{2} \mathrm{O}$, and $\mathrm{H}_{3} \mathrm{O}^{+}$(units of $\mathrm{kJ} \mathrm{mol}^{-1}$ )

\begin{tabular}{lllll}
\hline$E_{\mathrm{Au}^{3+}}$ & $E_{\mathrm{Au}^{+}}$ & $E_{\mathrm{DMH}}$ & $E_{\mathrm{H}_{2} \mathrm{O}}$ & $E_{\mathrm{H}_{3} \mathrm{O}^{+}}$ \\
\hline
\end{tabular}

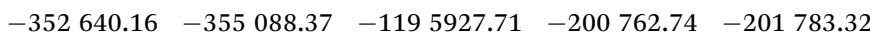

Table 2 Structures and energetic data calculated with B3LYP for the gold(I) complexes (units of $\mathrm{kJ} \mathrm{mol}^{-1}$ )

\begin{tabular}{llll}
\hline Number & Structure & $E_{\text {complexes }}$ & $E_{\text {bonding }}$ \\
\hline $\mathrm{a}$ & $2 \mathrm{~N}(2)-\mathrm{Au}$ & -2744863.54 & -39.08 \\
$\mathrm{~b}$ & $2 \mathrm{~N}(1)-\mathrm{Au}-4 \mathrm{~N}(1)$ & -2744847.35 & -55.27 \\
$\mathrm{c}$ & $4 \mathrm{~N}(2)-\mathrm{Au}$ & -2744830.70 & -71.92
\end{tabular}

Table 3 Structures and energetic data calculated with B3LYP for the gold(III) complexes (units of $\mathrm{kJ} \mathrm{mol}^{-1}$ )

\begin{tabular}{llll}
\hline Number & Structures & $E_{\text {complexes }}$ & $E_{\text {bonding }}$ \\
\hline $\mathrm{a}$ & $2 \mathrm{~N}(4)-\mathrm{Au}$ & -5133369.61 & -1100.95 \\
$\mathrm{~b}$ & $4 \mathrm{~N}(4)-\mathrm{Au}$ & -5133267.69 & -999.03 \\
$\mathrm{c}$ & $2 \mathrm{~N}(3)-\mathrm{Au}-4 \mathrm{~N}(1)$ & -5133340.45 & -1071.79 \\
$\mathrm{~d}$ & $2 \mathrm{~N}(3)-\mathrm{Au}-4 \mathrm{~N}(1)$ & -5133340.23 & -1071.57 \\
$\mathrm{e}$ & $2 \mathrm{~N}(3)-\mathrm{Au}-4 \mathrm{~N}(1)$ & -5133339.95 & -1071.29 \\
$\mathrm{f}$ & $2 \mathrm{~N}(3)-\mathrm{Au}-4 \mathrm{~N}(1)$ & -5133339.60 & -1070.94 \\
$\mathrm{~g}$ & $2 \mathrm{~N}(2)-\mathrm{Au}-4 \mathrm{~N}(2)$ & -5133310.78 & -1042.12 \\
$\mathrm{~h}$ & $2 \mathrm{~N}(2)-\mathrm{Au}-4 \mathrm{~N}(2)$ & -5133305.50 & -1036.83 \\
$\mathrm{i}$ & $2 \mathrm{~N}(1)-\mathrm{Au}-4 \mathrm{~N}(3)$ & -5133283.83 & -1015.17 \\
$\mathrm{j}$ & $2 \mathrm{~N}(1)-\mathrm{Au}-4 \mathrm{~N}(3)$ & -5133269.90 & -1001.24 \\
$\mathrm{k}$ & $2 \mathrm{~N}(1)-\mathrm{Au}-4 \mathrm{~N}(3)$ & -5133269.89 & -1001.23 \\
$\mathrm{l}$ & $2 \mathrm{~N}(1)-\mathrm{Au}-4 \mathrm{~N}(3)$ & -5133287.51 & -1018.85
\end{tabular}

indicate that gold(III) complexes were much more stable in the DMH-based gold electroplating electrolyte, so $\mathrm{Au}^{3+}$ is the appropriate gold source for the DMH-based gold electroplating electrolyte to get greater cathodic polarization. Furthermore, with the higher bonding energy, the structure $2 \mathrm{~N}(4)-\mathrm{Au}$ of gold(III) complexes possessed high stability in the gold electroplating electrolyte. The conclusions of the quantum chemical calculations proved that the most stable form of gold ion was $\left[\mathrm{Au}(\mathrm{DMH})_{4}\right]^{-}$with $2 \mathrm{~N}(4)-\mathrm{Au}$ coordination structure in the gold electroplating electrolyte.

The results of the quantum chemical calculations confirmed that $\mathrm{Au}^{3+}$ is the appropriate gold source for the DMH-based gold electroplating electrolyte and $\left[\mathrm{Au}(\mathrm{DMH})_{4}\right]^{-}$with $2 \mathrm{~N}(4)-\mathrm{Au}$ coordination structure is the most stable form of gold(III)complexes in the DMH-based gold electroplating electrolyte. The influences of gold ions and $\mathrm{DMH}$ on the cyanide-free gold electrodeposition process were further studied to perfect the cyanide-free gold electroplating electrolyte.

\subsection{Cathodic polarization measurement}

Based on above quantum chemical calculations, $\mathrm{Au}^{3+}$ and $\mathrm{DMH}^{-}$can form a stable $2 \mathrm{~N}(4)-\mathrm{Au}$ coordination complex $\left[\mathrm{Au}(\mathrm{DMH})_{4}\right]^{-}$in the cyanide-free gold electroplating electrolyte. Besides the coordination behavior, DMH can adsorb on the nickel substrate and gold surface with high stability, ${ }^{47}$ which can improve the cathodic polarization and the performance of the gold electrodeposit. Therefore, it is important to further optimize the concentration of $\mathrm{DMH}$ for excellent performance of the gold electrodeposit in this study. Cathodic polarization curves were employed to study the influences of various DMH concentrations on the gold electrodeposition process. Fig. 4 displays the cathodic polarization curves on the Pt-RDE at $600 \mathrm{rpm}$ in the DMH-based gold electroplating electrolytes with various DMH concentrations. Obviously, the polarization curve measured with the electrolyte in the absence of DMH increased

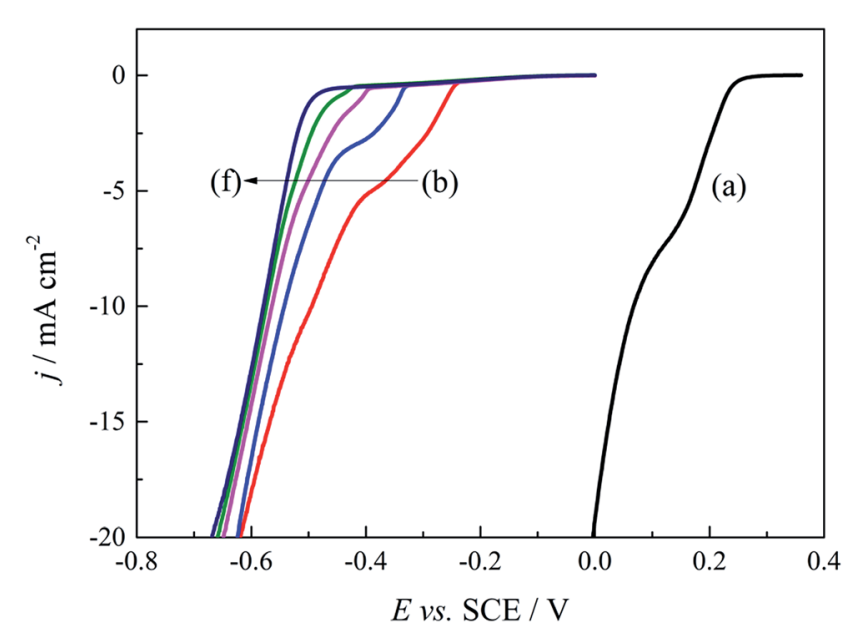

Fig. 4 Cathodic polarization curves on the Pt-RDE at $600 \mathrm{rpm}$ in the gold electroplating electrolytes with various $\mathrm{DMH}$ concentrations: (a) $0 \mathrm{~mol} \mathrm{~L}$, (b) $0.10 \mathrm{~mol} \mathrm{~L}^{-1}$, (c) $0.20 \mathrm{~mol} \mathrm{~L}^{-1}$, (d) $0.30 \mathrm{~mol} \mathrm{~L}^{-1}$, (e) $0.45 \mathrm{~mol} \mathrm{~L}^{-1}$, and (f) $0.60 \mathrm{~mol} \mathrm{~L}^{-1}$. 
rapidly at $0.260 \mathrm{~V}$, while the polarization curves measured in the presence of $\mathrm{DMH}$ all rise at potentials more negative than $-0.240 \mathrm{~V}$. The more than $500 \mathrm{mV}$ negative shift of the onset potential demonstrates a significant kinetic difference between the solutions on the Pt-RDE without and with DMH as the complexing agent. The contrast of Fig. 4(b)-(f) revealed that the sharp increase in the potential of the cathodic polarization curves is negatively shifted with the increase of the DMH concentration, while the shift is unobvious when the DMH concentration is more than $0.30 \mathrm{~mol} \mathrm{~L}^{-1}$. Thus, $0.30 \mathrm{~mol} \mathrm{~L}^{-1}$ may be the appropriate $\mathrm{DMH}$ concentration applied in the investigated cyanide-free gold electroplating electrolyte.

\subsection{Micromorphology of gold electrodeposits}

The morphology of the gold electrodeposits obtained from cyanide-free gold electroplating electrolyte without and with $\mathrm{DMH}$ were further studied to evaluate the influence of $\mathrm{DMH}$ on the gold electrodeposition process. The appearance of the gold electrodeposits obtained from the electrolyte without DMH was reddish brown and a rough surface with severe pitting. ${ }^{47}$ Correspondingly, the gold electrodeposit obtained from the electrolyte with $\mathrm{DMH}$ was more uniform and smooth with smaller crystal particles. The SEM images shown in Fig. 5 were employed to further study the influence of the DMH concentration on the surface micromorphology of the gold electrodeposits.

The SEM images displayed in Fig. 5 confirmed that the gold electrodeposit obtained from the electrolyte in the absence of $\mathrm{DMH}$ was much rougher with bigger particles than that from the electrolytes in the presence of various DMH concentrations. Additionally, the performance of the gold electrodeposits can be improved with the increase of the $\mathrm{DMH}$ concentrations, as displayed in Fig. 5(a)-(e). The size of the crystal particles decreased with increasing DMH concentration, however, it only decreased slightly when the DMH concentration was more than $0.30 \mathrm{~mol} \mathrm{~L}^{-1}$. In summary, ensuring all $\mathrm{Au}^{3+}$ in the solution forms a stable gold(III) complex and considering the influence of $\mathrm{DMH}$ on the cathodic polarization, the optimum DMH concentration was determined as $0.30 \mathrm{~mol} \mathrm{~L}^{-1}$ in the DMHbased cyanide-free gold electroplating electrolyte for subsequent investigations.

\subsection{Kinetic features}

Cyclic voltammogram measurements performed in the absence and presence of $0.30 \mathrm{~mol} \mathrm{~L}^{-1} \mathrm{DMH}$ at various scan rates $(10,20$, $40,60,80$, and $100 \mathrm{mV} \mathrm{s}^{-1}$ ) on a GCE were employed to analyze
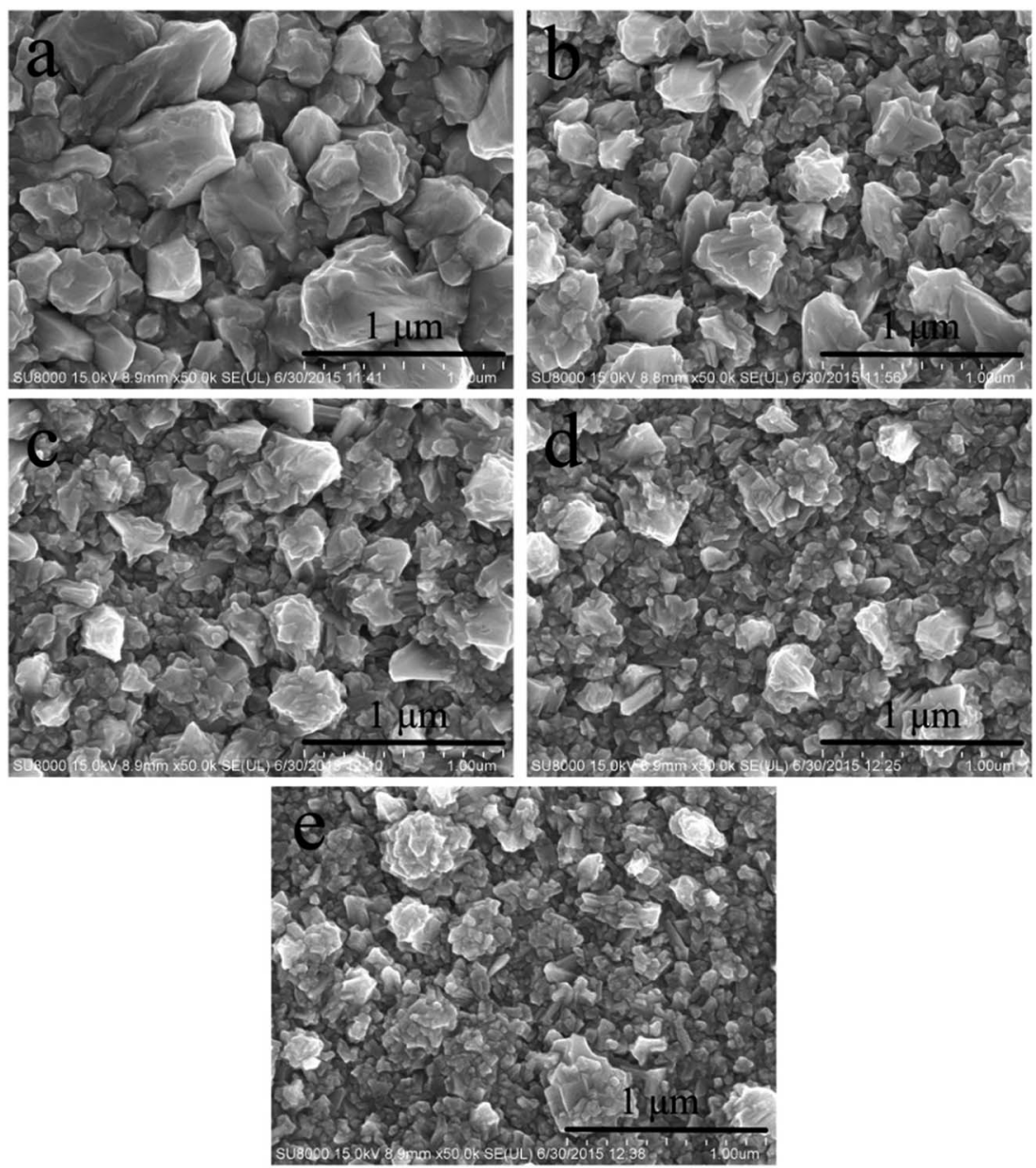

Fig. 5 SEM images of gold electrodeposits obtained from the gold electroplating electrolytes with various DMH concentrations: (a) 0.10 mol $\mathrm{L}^{-1}$, (b) $0.20 \mathrm{~mol} \mathrm{~L}^{-1}$, (c) $0.30 \mathrm{~mol} \mathrm{~L}^{-1}$, (d) $0.45 \mathrm{~mol} \mathrm{~L}^{-1}$, and (e) $0.60 \mathrm{~mol} \mathrm{~L}^{-1}$. 
the gold electrodeposition behavior, the control step of the gold electrodeposition, the transfer coefficient, and the diffusion coefficient influenced by DMH, as shown in Fig. 6 .

As displayed in Fig. 6, the reduction peaks of the gold electroplating process in the absence and presence of $\mathrm{DMH}$ all shifted to more negative potentials with the increase of the scan rate, indicating that the gold electrodeposition is an irreversible process both with and without DMH as the complexing agent. At the initial scan along the negative direction, the cyclic voltammograms of the gold electrodeposition in the presence of $0.30 \mathrm{~mol} \mathrm{~L}^{-1} \mathrm{DMH}$ all increase at more negative potentials than that in the absence of DMH. Furthermore, the cathodic density peaks increase with the increase of the scan rate in the electrolytes both with and without DMH. The cyclic voltammograms of the electrolytes with DMH as the complexing agent revealed a much lower cathodic density peak than that of the electrolytes in the absence of DMH at the same scan rate.

The linear relationship between the peak current density $\left(j_{\mathrm{p}}\right)$ and the square root of the scan rate $\left(v^{1 / 2}\right)$ is the characteristic of a diffusion-controlled reaction, which can be expressed as eqn (3):
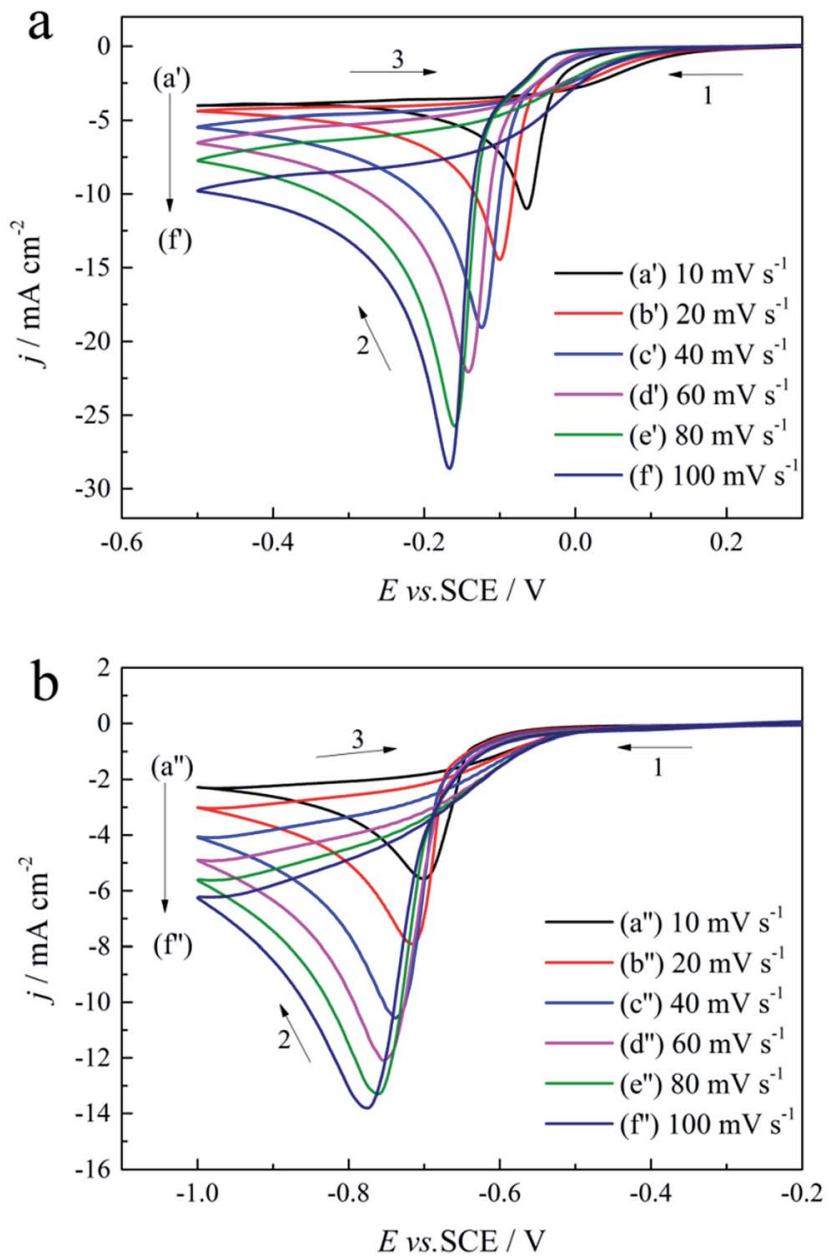

Fig. 6 Cyclic voltammograms with different scan rates on a GCE of the gold electroplating electrolytes: (a) without $\mathrm{DMH}$ and (b) with $0.30 \mathrm{~mol} \mathrm{~L}^{-1} \mathrm{DMH}$.

$$
j_{\mathrm{p}}=0.4958(n F)^{3 / 2}(\alpha D v)^{1 / 2}(R T)^{-1 / 2} c
$$

where $j_{\mathrm{p}}$ is the peak current density, $n$ is the number of electrons involved in the reaction ( $n=3$ in this study), $F$ is the Faraday constant, $\alpha$ is the charge transfer coefficient, $D$ is the diffusion coefficient, $v$ is the scan rate, $R$ is the gas constant, $T$ is the temperature $(T=318 \mathrm{~K})$, and $c$ is the concentration of electroactive species in the electrolyte $\left(c=0.025 \mathrm{~mol} \mathrm{~L}^{-1}\right)$. The fitted $j_{\mathrm{p}}$ vs. $v^{1 / 2}$ plots, presented in Fig. 7 , possess a zero intercept, indicating that the electrodeposition process is diffusion controlled in the studied gold electroplating electrolyte, both with and without $0.30 \mathrm{~mol} \mathrm{~L}^{-1} \mathrm{DMH}$ as the complexing agent.

The Delahay equations, ${ }^{48}$ as shown in eqn (4) and (5), were used to analyze the kinetic features of the gold electrodeposition process based on the cyclic voltammograms.

$$
\begin{gathered}
E_{\mathrm{p}}-E_{\mathrm{p} / 2}=-1.857 R T /(\alpha n F) \\
E_{\mathrm{p}}=K-\frac{2.3 R T}{2 \alpha n F} \log \nu
\end{gathered}
$$

where

$$
K=E_{\mathrm{C}}^{0}-\frac{R T}{\alpha n F}\left[0.78-\frac{2.3}{2} \log \left(\frac{\alpha n F D}{\left(K_{\mathrm{s}}\right)^{2} R T}\right)\right]
$$

$E_{\mathrm{p}}$ is the peak potential, $E_{\mathrm{p} / 2}$ is the potential at half of the peak current density, $E_{\mathrm{C}}^{0}$ is the standard potential, and $K_{\mathrm{s}}$ is the kinetic constant. As presented in Fig. 8, the fitted $E_{\mathrm{p}} v s . \log v$ plots possess a linear feature, which proves that the gold electrodeposition in the absence or presence of $\mathrm{DMH}$ is a typical irreversible process under diffusion control. The kinetic features obtained from the cyclic voltammograms are listed in Table 4.

As displayed in Table 4 , the transfer coefficients $(\alpha)$ are calculated from the cyclic voltammetry curves according to eqn (4); the $\alpha$ of the gold electroplating in the electrolyte without $\mathrm{DMH}$ is 0.705 , bigger than that of the electrolyte with DMH as

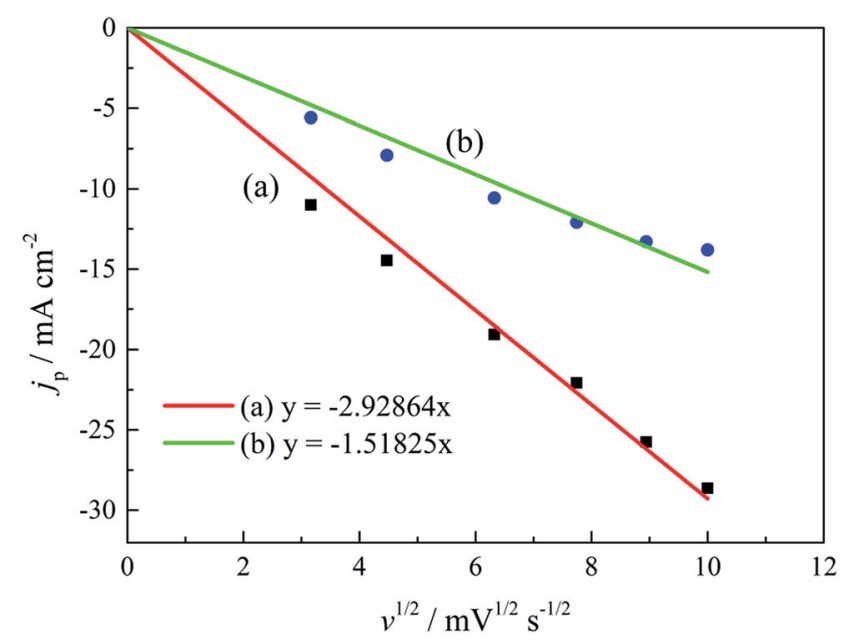

Fig. 7 The peak current density $\left(j_{p}\right)$ of cyclic voltammograms with various scan rates versus $v^{1 / 2}$ of the gold electroplating electrolytes (a) without $\mathrm{DMH}$ and (b) with $0.30 \mathrm{~mol} \mathrm{~L}^{-1} \mathrm{DMH}$. 


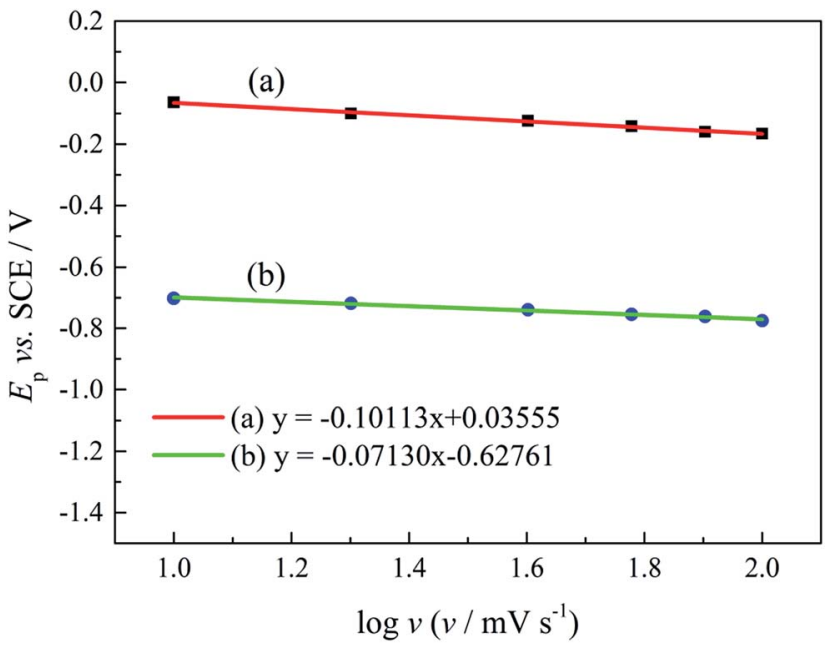

Fig. 8 The peak potential $\left(E_{\mathrm{p}}\right)$ of cyclic voltammograms with various scan rates versus log $v$ of the gold electroplating electrolytes (a) without DMH and (b) with $0.30 \mathrm{~mol} \mathrm{~L}^{-1} \mathrm{DMH}$.

Table 4 The transfer coefficients $(\alpha)$ calculated from cyclic voltammetry curves at various scan rates on a GCE

\begin{tabular}{|c|c|c|c|c|}
\hline \multirow[b]{2}{*}{$v / \mathrm{mV} \mathrm{s}^{-1}$} & \multicolumn{2}{|c|}{ DMH: $0 \mathrm{~mol} \mathrm{~L}^{-1}$} & \multicolumn{2}{|c|}{ DMH: $0.30 \mathrm{~mol} \mathrm{~L}^{-1}$} \\
\hline & $E_{\mathrm{p}}-E_{\mathrm{p} / 2} / V$ & $\alpha$ & $\begin{array}{l}E_{\mathrm{p}}- \\
E_{\mathrm{p} / 2} / V\end{array}$ & $\alpha$ \\
\hline 10 & -0.022 & 0.771 & -0.041 & 0.414 \\
\hline 20 & -0.024 & 0.707 & -0.033 & 0.514 \\
\hline 40 & -0.025 & 0.678 & -0.041 & 0.414 \\
\hline 60 & -0.027 & 0.628 & -0.051 & 0.333 \\
\hline 80 & -0.024 & 0.707 & -0.047 & 0.361 \\
\hline 100 & -0.023 & 0.737 & -0.053 & 0.320 \\
\hline Average & & 0.705 & & 0.393 \\
\hline
\end{tabular}

the complexing agent, which is 0.393 . The almost doubling of $\alpha$ demonstrates that the electron transfer of the gold electrodeposition process was obviously influenced by the DMH in the electrolyte as the complexing agent for $\mathrm{Au}^{3+}$. Following eqn (3) and the fitted $j_{\mathrm{p}} v s . v^{1 / 2}$ plots, the diffusion coefficient $(D)$ of ions in the electrolyte were calculated as $8.69 \times 10^{-6} \mathrm{~cm}^{2} \mathrm{~s}^{-1}$ and $4.19 \times 10^{-6} \mathrm{~cm}^{2} \mathrm{~s}^{-1}, 49$ respectively, indicating that $D$ was reduced with the addition of $\mathrm{DMH}$ in the electrolyte. It indicated that with $\mathrm{DMH}$ as the complexing agent for $\mathrm{Au}^{3+}$ in the gold electroplating electrolyte, the ion transfer was inhibited. In conclusion of the kinetic features based on the cyclic voltammogram measurements, the electrodeposition processes are both irreversible under diffusion control in the studied gold electroplating electrolyte, both with and without $0.30 \mathrm{~mol} \mathrm{~L}^{-1}$ $\mathrm{DMH}$ as the complexing agent. The ion and electron transfer of the gold electrodeposition process were obviously inhibited by $\mathrm{DMH}$ in the electrolyte as the complexing agent for $\mathrm{Au}^{3+}$.

\subsection{Nucleation mechanism}

The initial nucleation mechanism and growth stage of the gold electrodeposits on the cathode during the electroplating process can be used to derive the influence of DMH on the gold electrodeposition behavior. Potentiostatic current transient curves on a GCE from electrolytes in the absence of DMH are presented in Fig. 9(a) and, comparatively, the measurements in the presence of various DMH concentrations are presented in Fig. 10. The Scharifker and Hills ( $\mathrm{SH}$ ) models for the limit cases of instantaneous and progressive nucleation were employed to analyze the current transient curves measured in this work. The SH models ${ }^{50-52}$ of 3-D instantaneous nucleation and progressive nucleation are shown in eqn (6) and (7), respectively:

$$
\begin{aligned}
& \left(\frac{j}{j_{\mathrm{m}}}\right)^{2}=1.9542\left(\frac{t}{t_{\mathrm{m}}}\right)^{-1}\left\{1-\exp \left[-1.2564\left(\frac{t}{t_{\mathrm{m}}}\right)\right]\right\}^{2} \\
& \left(\frac{j}{j_{\mathrm{m}}}\right)^{2}=1.2254\left(\frac{t}{t_{\mathrm{m}}}\right)^{-1}\left\{1-\exp \left[-2.3367\left(\frac{t}{t_{\mathrm{m}}}\right)^{2}\right]\right\}^{2}
\end{aligned}
$$

where $j$ and $t$ are the current density and measurement time, and $j_{\mathrm{m}}$ and $t_{\mathrm{m}}$ are the maximum current density and the corresponding time, respectively. All experimental current transient curves were transformed into non-dimensional plots of $\left(j / j_{\mathrm{m}}\right)^{2} v s$. $\left(t / t_{\mathrm{m}}\right)$ and all these plots were compared with theoretical current transient curves, as shown in Fig. 9(b) (without $\mathrm{DMH}$ ) and Fig. 11 (with DMH).

As shown in Fig. 9(a) and 10, potentiostatic current transient curves measured in the electrolytes without $\mathrm{DMH}$ or with various DMH concentrations; an increase in $j_{\mathrm{m}}$ and a decrease in $t_{\mathrm{m}}$ are significantly observed when the applied potential $\left(E_{\mathrm{ap}}\right)$
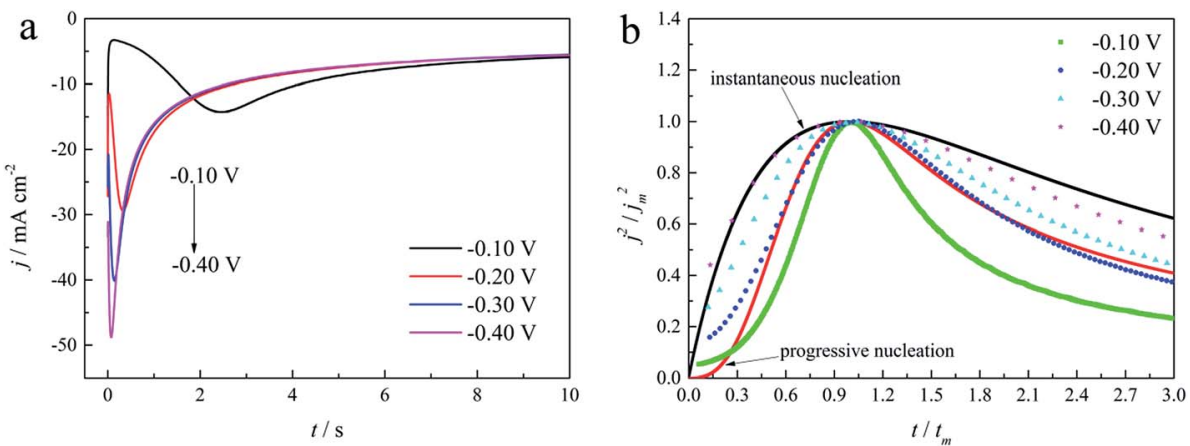

Fig. 9 (a) Current transient curves on the GCE of electrolyte without DMH under different $E_{\mathrm{ap}}$. (b) Non-dimensional plots of instantaneous and progressive nucleation of SH models with three-dimensional nuclei growth and experimental curves of the electrolyte without DMH. 

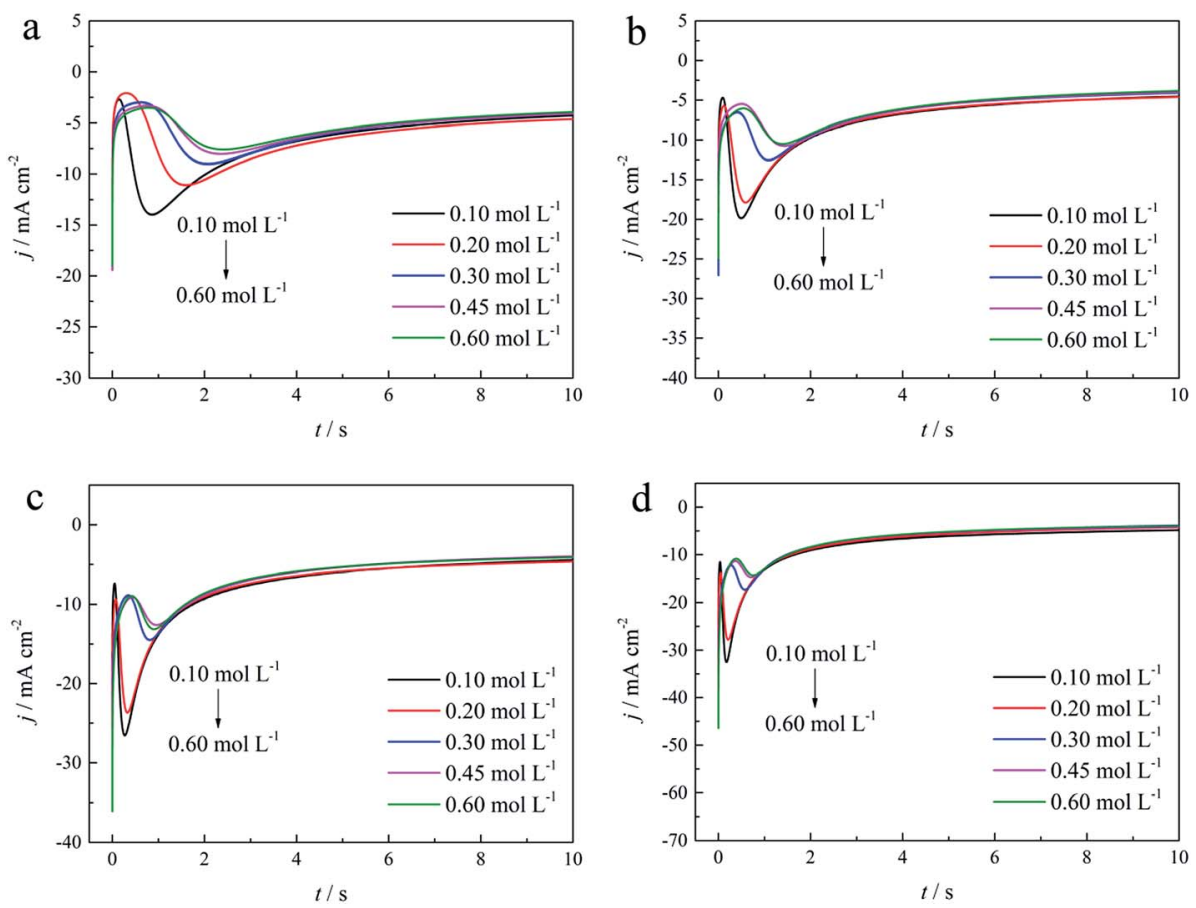

Fig. 10 Current transient curves on the GCE of different gold electroplating electrolytes with various DMH concentrations under different $E_{\text {ap }}$ : (a) $-0.70 \mathrm{~V}$, (b) $-0.75 \mathrm{~V}$, (c) $-0.80 \mathrm{~V}$, and (d) $-0.85 \mathrm{~V}$.
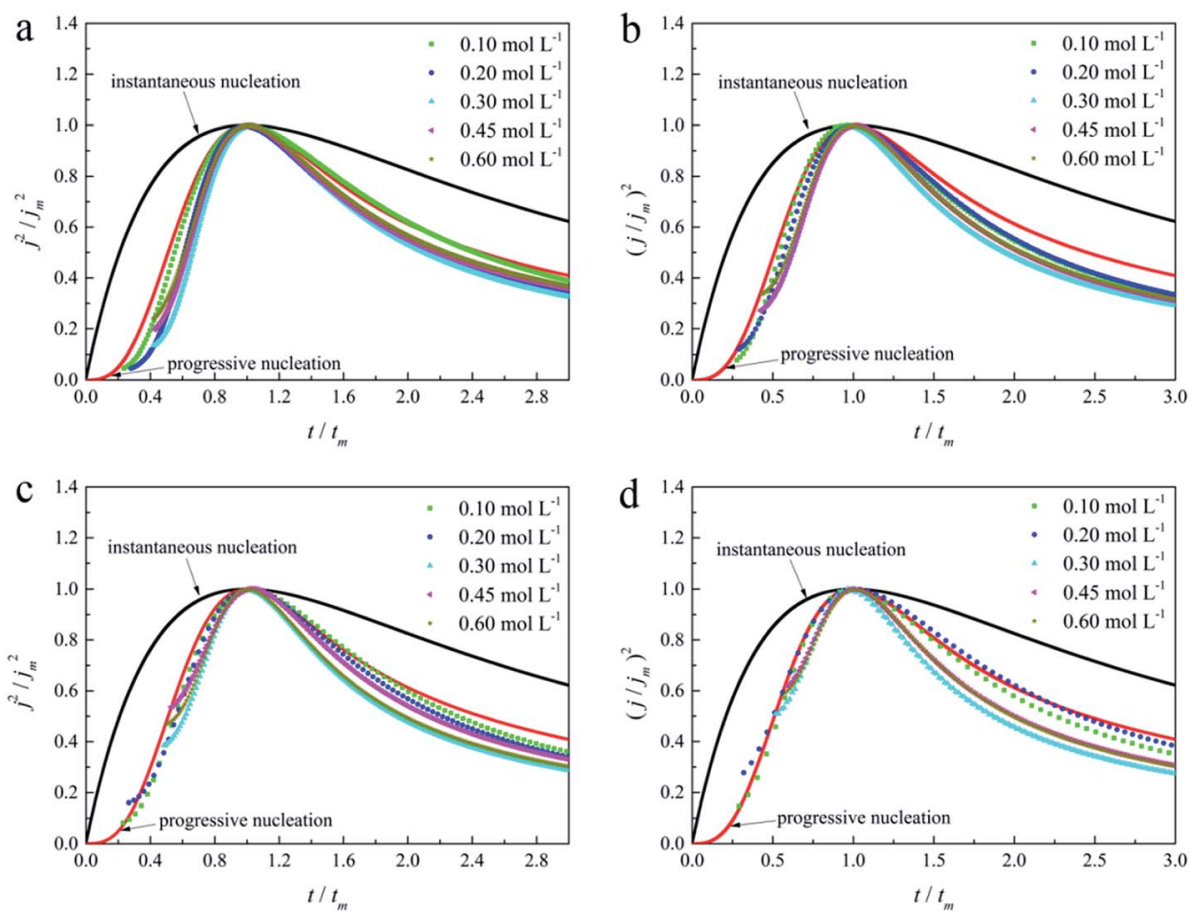

Fig. 11 Non-dimensional plots of instantaneous and progressive nucleation of SH models with three-dimensional nuclei growth and experimental curves of the gold electroplating electrolytes with various $\mathrm{DMH}$ concentrations under different $E_{\mathrm{ap}}$ : (a) $-0.70 \mathrm{~V}$, (b) $-0.75 \mathrm{~V}$, (c) $-0.80 \mathrm{~V}$, and (d) $-0.85 \mathrm{~V}$.

was set to more negative values. The existence of a current density peak in the current transient curves indicates that the charge transfer reaction controls the reaction kinetics at the early stages of the gold electrodeposition process, showing that there is a nucleation stage preceding the growth of the gold deposit. All these current transient curves can reach a steady 
state of current density at about $10 \mathrm{~s}$ of measurement, demonstrating that after the nucleation stage the reaction is under diffusion control. Moreover, as shown in Fig. 10, when the DMH concentrations increased, a decrease in $j_{\mathrm{m}}$ and an increase in $t_{\mathrm{m}}$ occurred at the same $E_{\text {ap }}$, and the $j_{\mathrm{m}}$ of DMH with 0.10 and $0.20 \mathrm{~mol} \mathrm{~L}^{-1}$ concentrations are obviously higher than that of other concentrations.

As in the non-dimensional plots from electrolyte without DMH displayed in Fig. 9(b), when the $E_{\text {ap }}$ was set to more negative values, the non-dimensional plots of experimental data transferred from following the model of progressive nucleation to instantaneous nucleation. This indicates that the nucleation model of the gold electrodeposition in the absence of $\mathrm{DMH}$ complexing agent is mostly influenced by $E_{\text {ap. }}$. In contrast with the plots from electrolytes with DMH shown in Fig. 11, the nucleation model of the gold electrodeposition process with various DMH concentrations under different $E_{\text {ap }}$ is progressive nucleation. The gold nucleation process is slightly influenced by $E_{\text {ap }}$ when the DMH concentrations are 0.10 and $0.20 \mathrm{~mol} \mathrm{~L}^{-1}$, while it is hardly influenced by $E_{\text {ap }}$ when the DMH concentrations are $0.30,0.45$, and $0.60 \mathrm{~mol} \mathrm{~L}^{-1}$.

Table 5 The parameters of the $\mathrm{SH}$ models of progressive and instantaneous nucleation ${ }^{50}$

\begin{tabular}{ll}
\hline Progressive nucleation & Instantaneous nucleation \\
\hline$t_{\mathrm{m}}=\left(\frac{4.6733}{A N_{\infty} \pi k^{\prime} D}\right)^{\frac{1}{2}}$ & $t_{\mathrm{m}}=\frac{1.2564}{N \pi k D}$ \\
$j_{\mathrm{m}}=0.4615 n F D^{3 / 4} c\left(A N_{\infty} k^{\prime}\right)^{1 / 4}$ & $j_{\mathrm{m}}=0.6382 \pi F D c(N k)^{1 / 2}$ \\
$j_{\mathrm{m}}{ }^{2} t_{\mathrm{m}}=0.2598(n F c)^{2} D$ & $j_{\mathrm{m}}{ }^{2} t_{\mathrm{m}}=0.1629(n F c)^{2} D$ \\
$k^{\prime}=\frac{4}{3}\left(\frac{8 \pi c M}{\rho}\right)^{\frac{1}{2}}$ & $k=\left(\frac{8 \pi c M}{\rho}\right)^{\frac{1}{2}}$
\end{tabular}

During the metal electrodeposition process, based on the instantaneous and progressive nucleation models, parameters of diffusion coefficient, nucleation rate constant, and nucleation density can be acquired using $j_{\mathrm{m}}$ and $t_{\mathrm{m}}$ with the equations displayed in Table 5, where $A$ is the nucleation rate constant $\left(\mathrm{cm}^{-2} \mathrm{~s}\right)$, $N$ and $N_{\infty}$ are the nuclei number on the electrode $\left(\mathrm{cm}^{-2}\right), n$ is the number of electrons involved in the reaction ( $n=3$ in this study), $F$ is the Faraday constant, $D$ is the diffusion coefficient $\left(\mathrm{cm}^{2} \mathrm{~s}^{-1}\right)$, $c$ is the concentration of electroactive species in the electrolyte ( $\left.c=0.025 \mathrm{~mol} \mathrm{~L}^{-1}\right), M$ is the molar mass of gold $(M=$ $\left.196.97 \mathrm{~g} \mathrm{~mol}^{-1}\right)$, and $\rho$ is the density of gold $\left(\rho=19.32 \mathrm{~g} \mathrm{~cm}^{-3}\right)$.

Based on the study of current transient curves, in the electrolyte without $\mathrm{DMH}$, the nucleation process is mostly influenced by $E_{\text {ap }}$, rather than following the instantaneous or progressive nucleation model. The parameters of the electrolyte without DMH cannot be obtained using this method. The nucleation model for the gold electrodeposition process with various DMH concentrations under different $E_{\text {ap }}$ is progressive nucleation. The parameters of the nucleation rate of gold on the electrode $\left(A N_{\infty}\right)$, the density of the saturated gold nucleation number $\left(N_{\mathrm{S}}\right)$, and the epitaxial growth rate of the gold crystal $\left(K_{\mathrm{v}}\right)$ can be studied with eqn (8)-(10).

$$
A N_{\infty}=\frac{4.6733}{t_{\mathrm{m}}^{2} \pi k^{\prime} D}
$$

$$
N_{\mathrm{s}}=\left(\frac{A N_{\infty}}{2 k^{\prime} D}\right)^{\frac{1}{2}}
$$

$$
K_{\mathrm{v}}=\frac{j_{\mathrm{m}}}{n F}
$$

With the study of current transient curves in electrolytes with various DMH concentrations, following Table 5 and eqn (8)(10), the $A N_{\infty}, N_{\mathrm{s}}$, and $K_{\mathrm{v}}$ can be obtained, as listed in Table 6.

Table $6 A N_{\infty}, N_{\mathrm{s}}$ and $K_{\mathrm{v}}$ of gold on the GCE of the gold electroplating electrolytes with various DMH concentrations

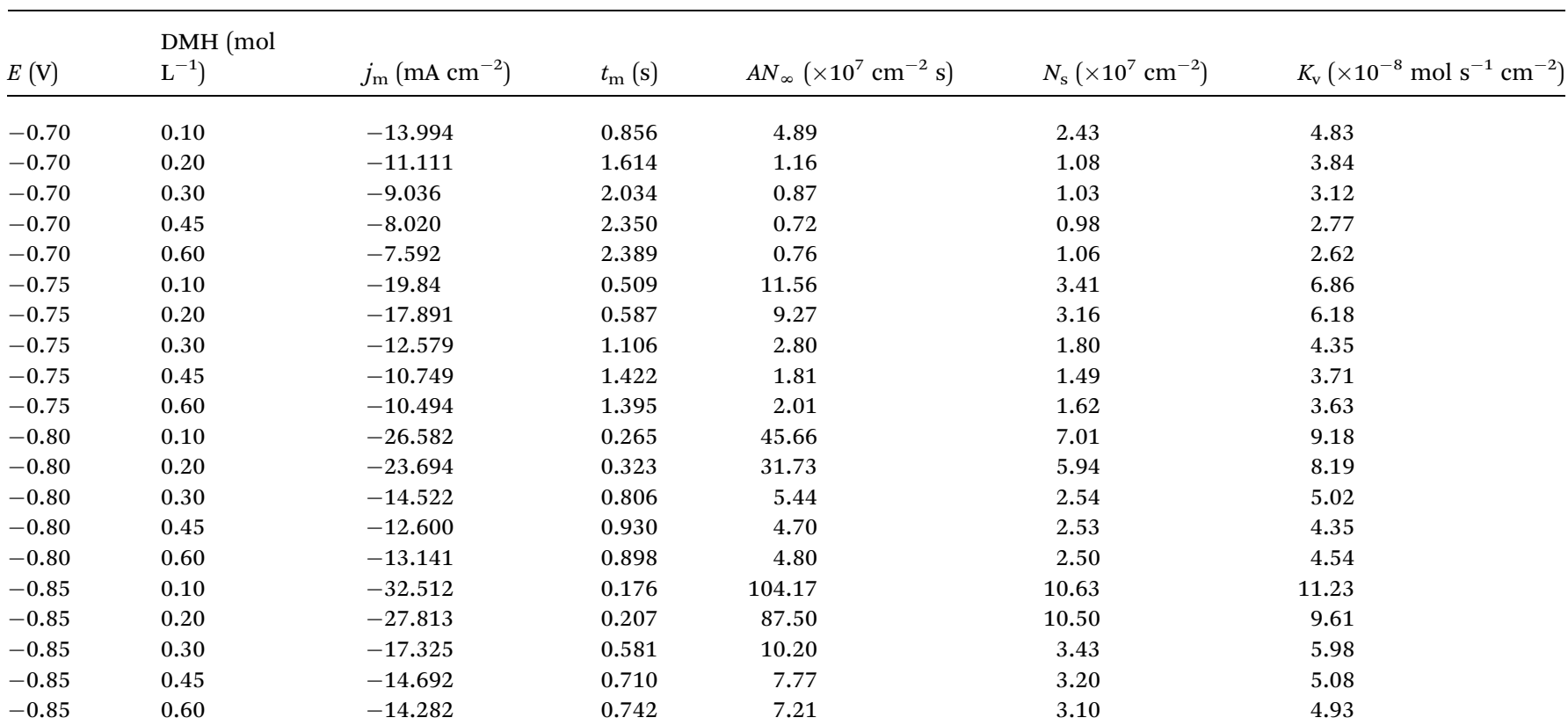


As shown in Table 6, at the same DMH concentration, $A N_{\infty}$, $N_{\mathrm{s}}$, and $K_{\mathrm{v}}$ all increased with the negative shift of $E_{\text {ap }}$, indicating that the growth rate of the crystal nucleus can be promoted by the negative shift of $E_{\mathrm{ap}}$. Additionally, at the same $E_{\mathrm{ap}}, A N_{\infty}, N_{\mathrm{s}}$, and $K_{\mathrm{v}}$ all decreased with the increase of the DMH concentration, indicating the inhibition influence of $\mathrm{DMH}$ on nucleation. However, when the DMH concentration reached $0.30 \mathrm{~mol} \mathrm{~L}^{-1}$, the downtrend of $A N_{\infty}, N_{\mathrm{s}}$, and $K_{\mathrm{v}}$ is diminished with the increase of $\mathrm{DMH}$ concentration, indicating that with the $\mathrm{DMH}$ concentration higher than $0.30 \mathrm{~mol} \mathrm{~L}^{-1}$, the growth rate of crystal nucleus was hardly influenced by the DMH concentration.

\section{Conclusion}

The results of the quantum chemical calculations showed that $2 \mathrm{~N}(-0.307)$ and $4 \mathrm{~N}(-0.218)$ of $\mathrm{DMH}$ were the most likely atoms to form coordinate bonds with gold ions. Three gold(I) complexes and 12 gold(III) complexes were possible structures of gold complexes in the electrolyte according to the charge distribution of DMH. With the higher bonding energy of gold(III) complexes than those of gold(I) complexes indicating that gold(III) complexes were much more stable in the DMHbased gold electroplating electrolyte, $\mathrm{Au}^{3+}$ was the appropriate gold source for the DMH-based gold electroplating electrolyte to get greater cathodic polarization. The structure $2 \mathrm{~N}(4)-\mathrm{Au}$ of gold(III) complexes possessed high stability in the gold electroplating electrolyte, which indicated that the most stable form of gold ion was $\left[\mathrm{Au}(\mathrm{DMH})_{4}\right]^{-}$with $2 \mathrm{~N}(4)-\mathrm{Au}$ coordination structure in the gold electroplating electrolyte.

The cathodic polarization of the gold electrodeposition was significantly enhanced with DMH as the complexing agent; the $500 \mathrm{mV}$ negative shift of the onset potential demonstrates a significant kinetic change compared with the electrolyte without DMH. The sharp increase in the potential of the cathodic polarization curves and the micromorphology of the gold electrodeposits was improved with the increase of the $\mathrm{DMH}$ concentration. Considering the influence of the DMH concentration on the cathodic polarization and the gold electrodeposit micromorphology, the optimum DMH concentration was determined as $0.30 \mathrm{~mol} \mathrm{~L}^{-1}$.

In conclusion of the kinetic features based on cyclic voltammograms measurements, the electrodeposition processes are both irreversible under diffusion control in the studied gold electroplating electrolyte, both with and without $0.30 \mathrm{~mol} \mathrm{~L}^{-1}$ $\mathrm{DMH}$ as the complexing agent. The transfer coefficients of the gold electroplating electrolytes in the absence and presence of $\mathrm{DMH}$ were 0.705 and 0.393 , respectively. The diffusion coefficients were calculated as $8.69 \times 10^{-6} \mathrm{~cm}^{2} \mathrm{~s}^{-1}$ and $4.19 \times 10^{-6}$ $\mathrm{cm}^{2} \mathrm{~s}^{-1}$ without and with $\mathrm{DMH}$, respectively. The ion and electron transfer of gold electrodeposition process were obviously inhibited by $\mathrm{DMH}$ in the electrolyte as the complexing agent for $\mathrm{Au}^{3+}$. The gold electrodeposition process displayed progressive nucleation with $\mathrm{DMH}$ as the complexing agent according to the $\mathrm{SH}$ nucleation model with various applied potentials. The growth rate of the crystal nucleus was reduced by $\mathrm{DMH}$ and promoted by the negative shift of $E_{\text {ap }}$, while when the $\mathrm{DMH}$ concentration was higher than $0.30 \mathrm{~mol} \mathrm{~L}^{-1}$, the growth rate of the crystal nucleus was hardly influenced by the DMH concentration.

\section{Conflicts of interest}

There are no conflicts to declare.

\section{Acknowledgements}

The authors acknowledge the support of the Fundamental Research Funds for the Central Universities (DUT16RC(3)084) and Supercomputing Center of Dalian University of Technology.

\section{References}

1 T. A. Green, Gold Bull., 2007, 40, 105-114.

2 A. P. OssMullane, S. J. Ippolito, Y. M. Sabri, V. Bansal and S. K. Bhargava, Langmuir, 2009, 25, 3845-3852.

3 L. Sus, Y. Okhremchuk, I. Saldan, O. Kuntyi, O. Reshetnyak and S. Korniy, Mater. Lett., 2015, 139, 296-299.

4 A. Benvidi, A. Dehghani-Firouzabadi, M. Mazloum-Ardakani, B.-B. F. Mirjalili and R. Zare, J. Electroanal. Chem., 2015, 736, 22-29.

5 E. V. Monaico, I. M. Tiginyanu, V. V. Ursaki, K. Nielsch, D. Balan, M. Prodana and M. Enachescu, J. Electrochem. Soc., 2017, 164, D179-D183.

6 Y. Dai, N. Wang, Y. Li, M. Yao, H. Gan and W. Hu, Fusion Eng. Des., 2016, 107, 51-57.

7 J. Luo, J. Yin, H. Zhang, M. Yao and W. Hu, Fusion Eng. Des., 2016, 113, 51-56.

8 L. Soleimany, A. Dolati and M. Ghorbani, J. Electroanal. Chem., 2010, 645, 28-34.

9 M. Hosseini and S. Ebrahimi, J. Electroanal. Chem., 2010, 645, 109-114.

10 T. Z. Sadyrbaeva, Sep. Purif. Technol., 2012, 86, 262-265.

11 S. Dimitrijevic, M. Rajcic-Vujasinovic and V. Trujic, Int. J. Electrochem. Sci., 2013, 8, 6620-6646.

12 A. He, Q. Liu and D. Ivey, J. Mater. Sci.: Mater. Electron., 2009, 20, 543-550.

13 J. Chen, Y. Fang, Q. Qiu, L. You, J. Song, G. Zhang, G. Chen and J. Sun, Green Chem., 2011, 13, 2339-2343.

14 B. A. Al-Maythalony, M. I. M. Wazeer and A. A. Isab, Inorg. Chim. Acta, 2009, 362, 3109-3113.

15 A. I. de Sá, S. Eugénio, S. Quaresma, C. M. Rangel and R. Vilar, Thin Solid Films, 2011, 519, 6278-6283.

16 M. J. -Liew, S. Sobri and S. Roy, Electrochim. Acta, 2005, 51, 877-881.

17 S. Sobri, S. Roy, D. Aranyi, P. M. Nagy, K. Papp and E. Kalman, Surf. Interface Anal., 2008, 40, 834-843.

18 N. Moghimian, M. Sam, J. D. Coelho, S. D. W. Warwick and R. B. Bhiladvala, Electrochim. Acta, 2013, 114, 643-648.

19 E. C. Estrine, S. Riemer, V. Venkatasamy, B. J. H. Stadler and I. Tabakovic, J. Electrochem. Soc., 2014, 161, D687-D696.

20 G. Z. Pavlovich and R. G. Luthy, Water Res., 1988, 22, 327336. 
21 E. K. Beloglazkina, A. G. Majouga, A. V. Mironov, A. V. Yudina, O. Y. Kuznetsova and N. V. Zyk, Polyhedron, 2014, 76, 45-50.

22 M. Puszyńska-Tuszkanow, T. Grabowski, M. Daszkiewicz, J. Wietrzyk, B. Filip, G. Maciejewska and M. CieślakGolonka, J. Inorg. Biochem., 2011, 105, 17-22.

23 K. Oyaizu, Y. Ohtani, A. Shiozawa, K. Sugawara, T. Saito and M. Yuasa, Inorg. Chem., 2005, 44, 6915-6917.

24 Y. Houndonougbo, C. Signer, N. He, W. Morris, H. Furukawa, K. G. Ray, D. L. Olmsted, M. Asta, B. B. Laird and O. M. Yaghi, J. Phys. Chem. C, 2013, 117, 10326-10335.

25 T. Wang, Y. Liang and Z. X. Yu, J. Am. Chem. Soc., 2011, 133, 9343-9353.

26 Z. Rinkevicius, X. Li, J. A. R. Sandberg, K. V. Mikkelsen and H. Ågren, J. Chem. Theory Comput., 2014, 10, 989-1003.

27 H. Henschel, J. C. A. Navarro, T. Yli-Juuti, O. KupiainenMäättä, T. Olenius, I. K. Ortega, S. L. Clegg, T. Kurtén, I. Riipinen and H. Vehkamäki, J. Phys. Chem. A, 2014, 118, 2599-2611.

28 C. Jung, L. K. Boateng, J. R. V. Flora, J. Oh, M. C. Braswell, A. Son and Y. Yoon, Chem. Eng. J., 2015, 264, 1-9.

29 B. Xu, W. Yang, Y. Liu, X. Yin, W. Gong and Y. Chen, Corros. Sci., 2014, 78, 260-268.

30 V. Jaiswal, R. B. Rastogi, J. L. Maurya, P. Singh and A. K. Tewari, RSC Adv., 2014, 4, 13438-13445.

31 Y. S. Mary, P. J. Jojo, C. Van Alsenoy, M. Kaur, M. S. Siddegowda, H. S. Yathirajan, H. I. S. Nogueira and S. M. A. Cruz, Spectrochim. Acta, Part A, 2014, 120, 340-350.

32 V. Arjunan, M. Kalaivani, M. K. Marchewka and S. Mohan, Spectrochim. Acta, Part A, 2013, 107, 90-101.

33 A. J. Cohen, P. Mori-Sánchez and W. Yang, Chem. Rev., 2012, 112, 289-320.

34 A. Ghosh, Chem. Rev., 2017, 117, 3798-3881.

35 S. Grimme, C. Bannwarth and P. Shushkov, J. Chem. Theory Comput., 2017, 13, 1989-2009.
36 X. Zhang, H. Dai, H. Yan, W. Zou and D. Cremer, J. Am. Chem. Soc., 2016, 138, 4334-4337.

37 F. Y. Guo, C. G. Long, J. Zhang, Z. Zhang, C. H. Liu and K. Yu, Appl. Surf. Sci., 2015, 324, 584-589.

38 C. I. Maxwell, A. A. Neverov, N. J. Mosey and R. Stan Brown, J. Phys. Org. Chem., 2014, 27, 419-429.

39 A. Shukla, E. Khan, K. Srivastava, K. Sinha, P. Tandon and V. R. Vangala, CrystEngComm, 2017, 19, 3921-3930.

40 H. Golchoubian and S. Koohzad, Transition Met. Chem., 2014, 39, 327-335.

41 A. Adebisi, I. N. Booysen, M. P. Akerman and B. Xulu, Transition Met. Chem., 2016, 41, 629-635.

42 M. K. Bharty, S. K. Kushawaha, U. K. Chaudhari, R. K. Dani, B. Maiti and R. J. Butcher, Transition Met. Chem., 2017, 42, 243-252.

43 F. Cheng, C. He and S. Yu, Transition Met. Chem., 2017, 42, 395-403.

44 A. Liu, X. Ren, M. An, J. Zhang, P. Yang, B. Wang, Y. Zhu and C. Wang, Sci. Rep., 2014, 4, 3837.

45 A. Liu, X. Ren, B. Wang, J. Zhang, P. Yang, J. Zhang and M. An, $R S C$ Adv., 2014, 4, 40930-40940.

46 Z. Feng, A. Liu, L. Ren, J. Zhang, P. Yang and M. An, J. Electrochem. Soc., 2016, 163, D764-D773.

47 X. Ren, Y. Song, A. Liu, J. Zhang, P. Yang, J. Zhang and M. An, RSC Adv., 2015, 5, 64997-65004.

48 A. J. Bard and L. R. Faulkner, Electrochemical Methods: Fundamentals and Applications, Wiley, 2000.

49 X. Ren, Y. Song, A. Liu, J. Zhang, P. Yang, J. Zhang, G. Yuan, M. An, H. Osgood and G. Wu, RSC Adv., 2015, 5, 6480664813.

50 B. Scharifker and G. Hills, Electrochim. Acta, 1983, 28, 879889.

51 P. Ren, H. Y. Deng, J. X. Zhang and N. Dai, J. Electrochem. Soc., 2016, 163, D309-D313.

52 P. Ren, N. Dai, H. Y. Deng and J. X. Zhang, J. Electrochem. Soc., 2015, 162, D9-D14. 